\title{
Changes in biomass of the species cupressus arizonica affected by zinc metal
}

\author{
Seyed Armin Hashemi \\ Department of Forestry, Lahijan Branch, Islamic Azad University, Lahijan, Iran \\ Email: hashemi@liau.ac.ir
}

Keywords: Cupressus arizonica, Phytoremediation, Zinc, Heavy metal.

\begin{abstract}
The matter of soil pollution by heavy metals caused to increase of concerns about environment. The present study has been done by the aim of investigation on zinc metal accumulation on cupressus arizonica. To achieving this goal the one-year Cupressus arizonica species seedlings were placed in vases. After the passage of each 55-day time periods from the growth of seedlings, the shoot, root and soil of seedlings were sampled. Results were studied using ANOVA test and Duncan test. The lowest concentration rate of zinc in Cupressus arizonica species organs in the first time period in the shoot and root was $5 \mathrm{~g}$ and $1.9 \mathrm{~g}$, respectively and in the second time period in the shoot and root was $2 \mathrm{~g}$ and $1.6 \mathrm{~g}$, respectively. Based on the researches, Cupressus arizonica species appropriate for refining zinc metal polluted soils.
\end{abstract}

\section{Introduction}

Nowadays, the environmental pollution is one of the most important matters that different societies are facing that. The pollution of soil by heavy metals is one of the most serious environmental problems at many points all over the world [1]. Entering of heavy metals to the environment and food cycles is very been noticed because of their toxicity and dangerous effect on human health and animals life. However, existence of some heavy metals like zinc ( $\mathrm{Zn})$ is necessary to growth of plant[2], but in high concentrations they can be toxic and due to stop in growth of plant[3]. However, zinc is an important vital element to life plant [4], but presence of more than $500 \mathrm{mg}$ of zinc in a kilogram dry matter of plant can be toxic to the animals that eat the plant [5]. One of the methods to bioremediation of polluted soils in which the pollution resistant plants uses to refinement the organic and inorganic compounds in the soil called phytoremediation. In this method the refining do by extracting and adsorption of pollutants in the plant structure [6]. Cupressus arizonica is an always green tree that uses to decorative and it is one of the most resistant cedars against hard situations all over the world. In their study have proved that the dry weight of the leaf in Arabiodopsis halleri plant (cadmium hyper accumulator) treated by $2.5 \mathrm{mg} / \mathrm{kg}$ concentration of cadmium was decreased up to $26 \%$ (compared to the control)[7]. In their research on Salsola Kali plant, introduced as the cadmium resistant plant, proved that the $5 \mathrm{mg} / 1$ treatment has caused $31 \%$ decrease in the dry weight of the aerial parts[8].

\section{Materials and Methods}

For implementing the research, annual seedlings and seeds of the same native smooth profile, were targeted. Cupressus arizonica had been selected among forest species, then the seedlings with the average height of $55 \mathrm{~cm}$, diameter collar $6 \mathrm{~mm}$ had been selected and prepared from one of agent conifer damping off located in Guilan province. Prepared seedlings had been paned to the greenhouse and kept there for twenty days to fit new situations.

For this purpose, the non-contaminated soil (natural clay used in this experiment) was taken as samples from the depths of $0-30 \mathrm{~cm}$ of agent conifer damping off some physicochemical characteristics of the soil were measured based on conventional methods in the country's water and soil Research Institute [1]. After the preparation of the soil, it had been dried and passed through a 2 $\mathrm{mm}$ sieve. The soil was kept in the shadow until the beginning of the experiment. 
The experiment was done five times in a factorial way and in a completely randomized design. Factors studied were of different levels of zinc and shoot and root Cupressus arizonica.

To prepare the soil contaminated with zinc, you must provide the proper salt of zinc after the preparation of soil so, for the preparation of zinc, zinc chloride salts made in march factory of Germany were used, In this study, the foliar spray on the soil with Zinc concentration of 0, 10, 20 and $40 \mathrm{mg} / \mathrm{L}$ was used and the amount of required solution was sprayed on the soil with manual spraying and mixed with the soil. When the soil contaminated with zinc was prepared, the seedlings that were the same in terms of diameter and height and etc. were chosen on the basis of required number and were planted in the pots based on experimental project. They were kept in the greenhouse and the moisture of the soil was maintained in much capacity With weight method, watering was done with distilled water in the event of need after two period of 55 days growth of seedlings, the plants were removed, root and shoot were separated, after rinsed with distilled water, They were dried with oven at a temperature of $70^{\circ} \mathrm{c}$, The soil samples were dried too and passed through a $2 \mathrm{~mm}$ sieve for analysis. The zinc volume in the plant samples was produced with dry digestion method by atomic absorption machine[10]. The data obtained from the tests were organized in SPSS software. For analyzing the data, first in order to determine the amount of accumulation of metal on ground and plant organs, they used variance analysis tests and in order to compare the effect of zinc concentration on shoot and root of the test used Duncan.

\section{Results}

\section{The effects of different concentrations of zinc and time on dry weight of shoot of Cupressus} arizonica

The results related to dry weight of shoot of Cupressus arizonica in 4 different concentrations of zinc metal and in two periods of time are shown in table 1 and figure 1 . Results showed that with accumulation of zinc in the plants dry weight of shoot decreased and about effect of time period, effect of concentration and their reciprocation effect on the amount of accumulation of zinc metal in the $5 \%$ is significant. So as a result with the probability level of $95 \%$ we can tell that there is a significant difference between all factors of soil with a view to concentration of zinc metal.

Table 1: The results of variance analysis of experimental treatments on dry weight of shoot of Cupressus arizonica

\begin{tabular}{|l|l|l|l|l|l|}
\hline Source & Type III Sum of Squares & df & Mean Square & F & Sig. \\
\hline time period & 11.481 & 1 & 11.481 & 78.311 & $0.000^{*}$ \\
\hline concentration & 64.216 & 3 & 21.405 & 146.004 & $0.000^{*}$ \\
\hline time period* concentration & 2.278 & 3 & 0.759 & 5.180 & $0.005^{*}$ \\
\hline Error & 4.691 & 32 & 0.147 & & \\
\hline Total & 82.667 & 39 & & & \\
\hline
\end{tabular}

*significance at $95 \%$ level, ns $=$ non-significant

Results of Duncan test show that there is a significant difference with the probability level of $95 \%$ in the dry weight of shoots with the foliar spray concentrations of $0,10,20$ and $40 \mathrm{mg} / \mathrm{L}$. The lowest dry weight in each time period is in the concentration level of $40 \mathrm{mg} / \mathrm{L}$ and its rate in the first and second time periods is $5 \mathrm{~g}$ and $2 \mathrm{~g}$, respectively, and the highest dry weight in each time period is observed in the control treatment and its rate in the first and second time periods is $9.8 \mathrm{~g}$ and $7 \mathrm{~g}$, respectively (figure 1). 


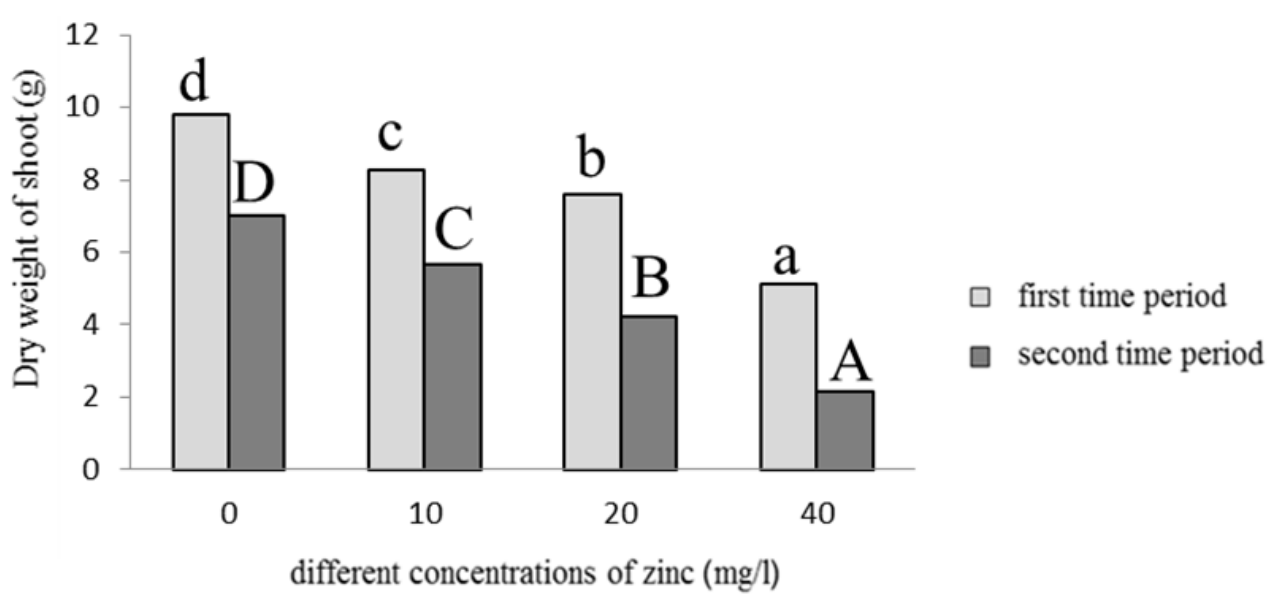

Figure1: The comparison between the amounts of the accumulation of zinc metal on dry weight of

Cupressus arizonica shoot affected by time.

\section{The effects of different concentrations of zinc and time on dry weight of root of Cupressus} arizonica

The results related to dry weight of root of Cupressus arizonica in 4 concentrations of zinc metal and two periods of time are shown in table 2 and figure 2 . The results showed that the dry weight of roots decreased by increasing of zinc accumulation in samples. And by using time periods and concentration, accumulation of zinc metal was significant at 5\% but about reciprocation effect of time and concentration of dry weight, it has not significant difference.

Table 2: The results of variance analysis of experimental treatments on dry weight of root of Cupressus arizonica

\begin{tabular}{|l|l|l|l|l|l|}
\hline Source & Type III Sum of Squares & df & Mean Square & F & Sig. \\
\hline time period & 5.177 & 1 & 5.177 & 59.953 & $0.000^{*}$ \\
\hline concentration & 27.461 & 3 & 9.154 & 106.010 & $0.000^{*}$ \\
\hline time period* concentration & 0.154 & 3 & 0.051 & 0.594 & $0.624^{\text {ns }}$ \\
\hline Error & 2.763 & 32 & 0.86 & & \\
\hline Total & 35.555 & 39 & & & \\
\hline
\end{tabular}

*significance at $95 \%$ level, ns= non-significant

Results of Duncan test show that there is a significant difference with the probability level of $95 \%$ in the dry weight of roots with the foliar spray concentrations of $0,10,20$ and $40 \mathrm{mg} / \mathrm{L}$. The lowest dry weight in each time period is in the concentration level of $40 \mathrm{mg} / \mathrm{L}$ and its rate in the first and second time periods is $1.9 \mathrm{~g}$ and $1.6 \mathrm{~g}$, respectively, and the highest dry weight in each time period is observed in the control treatment and its rate in the first and second time periods is $4 \mathrm{~g}$ and $3 \mathrm{~g}$, respectively (Figure 2).

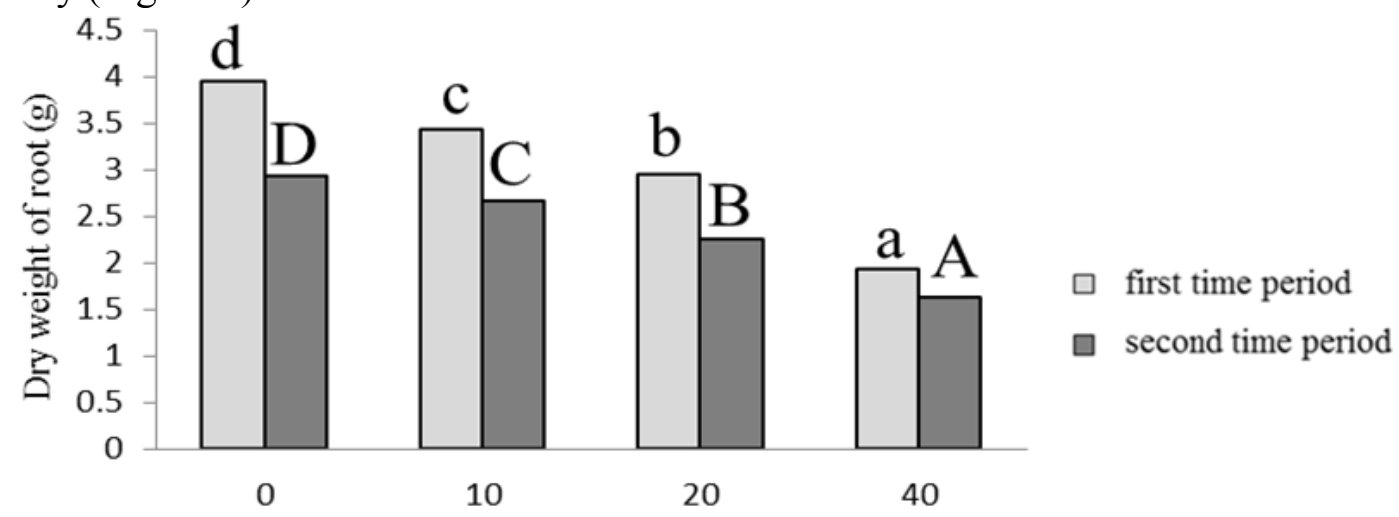

different concentrations of zinc $(\mathrm{mg} / \mathrm{l})$

Figure 2: The comparison between the amounts of the accumulation of zinc metal on dry weight of

Cupressus arizonica root affected by time. 


\section{Discussion and conclusions}

According to research about dry weight of shoot of Cupressus arizonica at two periods of time it was observable that the average of dry weight is observed in the control treatment and different levels of samples, a significant difference is at 95\% level and observes that dry weight of shoot of Cupressus arizonica decreases by increasing of zinc concentration in soil (table 1). So that maximum average of dry weight is observed in the control treatment and minimum average of dry weight was at $40 \mathrm{mg} / \mathrm{l}$ sample (figure1). in their research on Salsola Kali plant, introduced as the cadmium resistant plant, proved that the $5 \mathrm{mg} / 1$ treatment has caused $31 \%$ decrease in the dry weight of the aerial parts[9]. Also about dry weight of root of Cupressus arizonica that was at two periods of time, it is observable that increasing of zinc concentration in the soil and accumulation of zinc metal in the roots of plants the dry weight of roots decreased(table2). So that maximum average of dry weight is observed in the control treatment and minimum average of dry weight was at $40 \mathrm{mg} / \mathrm{l} \mathrm{sample}$ and there is significant difference between levels but in the mutual effects of time period and concentration in the dry weight of roots there is no significant difference (figure2).

\section{References}

[1] P.Blaster, S. Zimmermann, J. Luster \& W. Shotyk, Critical examination of trace element enrichment and depletion in soils: $\mathrm{As}, \mathrm{Cr}, \mathrm{Cu}, \mathrm{Ni}, \mathrm{Pb}$ and $\mathrm{Zn}$ in Swiss forest soil, Science of Total Environment. 249(2000): 257-280.

[2] C.Casia, E. Martinoia, and C.keller.Hyperaccumulation of cadmium and zinc in thlasp. Caerulescens and Arabidopsis halleri at the leaf cellular level,Plant physiology. 134(2004): 716725.

[3] M.J.Malakouti and M. Homaee. Fertile soils of arid and semi-arid full review. Second edition. Tarbiat Modarres University Press, Tehran, Iran, 2004.

[4] H. Marschner .Mineral nutrition of higher plants. Academic Press, London, UK,1995.

[5] S.P. McGrath, S.J. Dunham and R.L. Correl. Potential for phytoextraction of zinc and cadmium from soils using hyperaccumulator plants, in phytoremediation of contaminated soil and water. Terry, N. and Banuelos, G. Sd., CRC Press LLC, 2000.

[6] O.Atici, G.Agar, and P.Battal .Changes in phytohormone contents in chickpea seeds geminating under lead or zinc stress, Biologia plantarum, 49 (2)(2005): 215-222.

[7] M.Ali Ehyaei, and A.A. Behbahanizadeh. Methods Describe of chemical analysis of soil. Soil and Water Research Institute Publications,Iran, 1993.

[8] R.E.L.Westerma.Soil testing and plant analysis. SSSA. Madison wisconsin, USA, 1990.

[9] F.Wu, W.Yang, J.Zhang, and L. Zhou. Cadmium accumulation and growth responses of a poplar (Populus deltoides $\times$ Populus nigra) in cadmium contaminated purple soil and alluvial soil. Journal of Hazardous Materials 177(1-3)(2010): 268-273.

[10] G.Rosa., J. Peralta_videa, R., Montes, M., J. L Parsons. Cadmium uptake and translocation in tumbleweed (salsola kali), a potential cd-hyperaccumulator desert plant species: ICPLOES and XAS studies. Chemosphere 55(2004): 1159-1168. 